\title{
Mendeleev and the Rare-Earth Crisis
}

\author{
Pieter Thyssen* and Koen Binnemans \\ Laboratory of Inorganic Chemistry, Department of Chemistry, \\ KU Leuven - University of Leuven, Celestijnenlaan 200F, \\ P.O. BOX 2404, B-3001 Heverlee, Belgium \\ pieterthyssen@gmail.com
}

A few years ago, C. H. Evans noticed that historically "the rare-earth elements [had] created theoretical, as well as practical, headaches for chemists", but he admitted that "none [had been] greater than their proper position in the periodic table". ${ }^{1}$ According to Evans' opinion, "the interplay between Mendeleev's periodic system and the rare-earth elements is an interesting one, worthy of deeper analysis by future scholars." ${ }^{2}$ Following this suggestion, the substance of this paper will focus on Mendeleev's attitude towards the problematic accommodation of the rare-earth elements in the periodic system during the period 1869-1871. Henceforth, the term rare-earth crisis will be used to denote this accommodation issue.

There has been relatively little mention of the rare-earth crisis in the scholarly literature on Mendeleev and his periodic system. One notable exception is provided by the work of the Russian historian, D. N. Trifonov, who wrote two books on this subject-matter in Russian. Within the English scholarly literature, however, not much material is to be found. And yet, as will be argued in this paper, the rare-earth crisis embodied one of the greatest threats to the periodic system endangering some of the most cherished beliefs of Mendeleev.

Mendeleev himself referred to the rare earths as podvodnyi kamen (or underwater stone), also translated as 'stumbling block'. ${ }^{3}$ This evocative term already hints to what extent the placement of the rare-earth elements had troubled Mendeleev. After his discovery of the periodic system in February 1869, Mendeleev tirelessly laboured at the clarification, illustration, refinement, and optimisation of his periodic classification of the elements. Not surprisingly, the accommodation of

\footnotetext{
${ }^{1}$ Evans, C. H. "The Discovery of the Rare Earth Elements." Chemistry in Britain (1989): 880-882. (page 881)

2 "Introduction." In Episodes from the History of the Rare Earth Elements, ed. C. H. Evans, xviii. Dordrecht / Boston / London: Kluwer Academic Publishers, 1996.

${ }^{3}$ The authors thank M. Gordin for bringing this to our attention.
} 


\section{MENDELEEV AND THE RARE-EARTH CRISIS}

the rare-earth elements formed an important part of Mendeleev's research program, which lasted approximately two years - from 1869 till 1871. But at the end of 1871, Mendeleev threw in the towel, distancing himself from the various discussions concerning the placement of the rare earths which were held at the end of the nineteenth century.

Notwithstanding the fact that Mendeleev failed to resolve the rare-earth crisis, he definitely grasped the essence of the subject-matter better than any other chemist at the time. More importantly, the rare-earth elements also played a key role in inducing a number of important changes in Mendeleev's deep, almost philosophical, viewpoints with regard to the epistemological concept of a chemical element and the nature of elementary groups. The unexplainable properties and mystifying character of most rare earths made him question the current definition of a chemical element, as well as the validity and universality of the periodic law, and even led Mendeleev into hypothesising about the internal structure of matter and constitution of atoms.

The aim of this research paper is twofold: First of all, the early history of the accommodation of the rare-earth elements in the period 1869-1871 will be retraced. Secondly, and most importantly, the principal content of this paper intends to clarify some of Mendeleev's perceptions about primary and secondary groups, the elements as basic and simple substances, and the use of short and long form tables.

Since Mendeleev's viewpoints underwent some crucial changes around the second half of 1870, our historical argumentation will be built around two sections. The first section $(\$ 1)$ centres on the period from Mendeleev's discovery in February 1869 till the end of the first half of 1870. The second period which extended from the second half of 1870 to the end of 1871 will be dealt with in the second section $(\S 2)$. A summary of our principal conclusions can be found in $\S 3$.

\section{$\S 1$ THE PERIOD 1869-1870}

\section{I1 A Septuplet of Homeless Elements}

Nearly one hundred and fifty years ago, on the $17^{\text {th }}$ of February $1869,{ }^{4}$ a pamphlet was printed with the aim of circulating it among the most distinguished Russian and European chemists of that time

\footnotetext{
${ }^{4}$ All events in Russia are dated according to the Julian calendar (Old Style), which was used in Russia until January 1918 . It lagged 12 days behind the Gregorian calendar (New Style) in the 19th century, and 13 days in the 20th. For example, February 17, 1869 (Old Style) corresponds to March 1, 1869 (New Style), as can be seen on figure 2. Gregorian dates will be given for all events occurring outside Russia.
} 
(Figures 1, 2).5 The flyer was entitled An Attempted System of the Elements Based on Their Atomic Weight and Chemical Analogies and was signed by the 35 year old professor, D. MENDELEEV (Д. Менделеев), who at that time was holding the chair of general chemistry at the renowned university of St. Petersburg (Figure 3). The whole set of chemical elements had been logically laid down in six columns of increasing atomic weight and nineteen rows of natural groups, ${ }^{6}$ thus constituting the very first embodiment of the periodic law.

As compared to the modern periodic table, the Attempted System is rotated $90^{\circ}$ clockwise. The periods are lying vertically, rather than horizontally, and similar elements are grouped in horizontal rows, rather than vertical columns. Notice also that the rows of alkali metals and halogens are adjacent to one another (the noble gases were not yet discovered in 1869). Finally, many of the problematical elements are simply grouped on the right-hand side of the table in no particular order whatsoever.

\section{ОПЫТЪ СНСТЕМЫ ЯЛЕМЕНТОВЪ.}

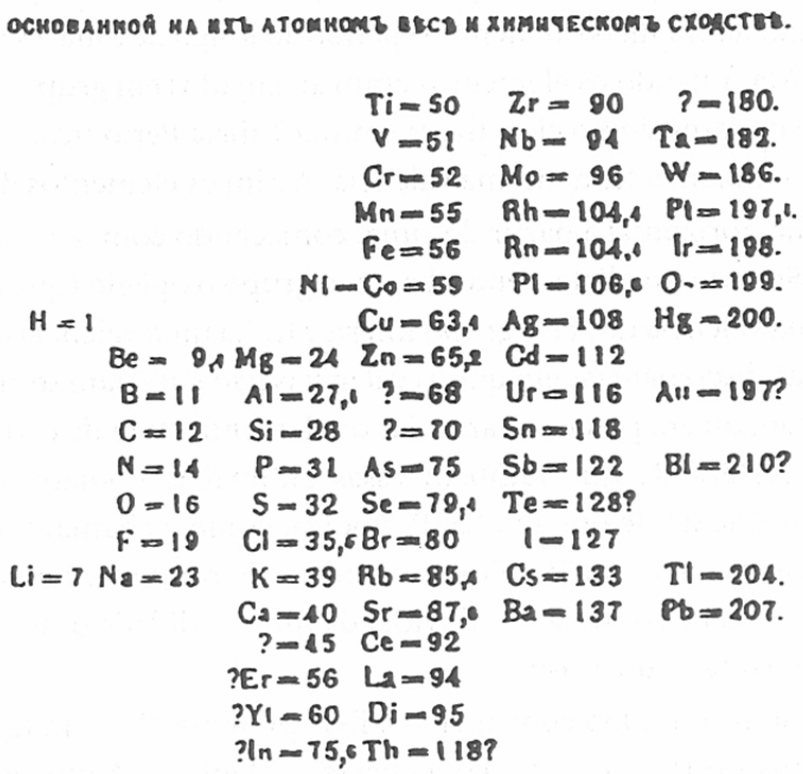

I. Menspasters
FIGURE 1. An attempted system of the elements based on their atomic weight and chemical analogies. A pamphlet with D. Mendeleev's first periodic system, distributed on the $17^{\text {th }}$ of February 1869.

\footnotetext{
${ }^{5}$ Mendeleev, D. I. "An Attempted System of the Elements Based on Their Atomic Weights and Chemical Analogies." 1869a. A total of two hundred single page copies were printed - 150 in Russian (Figure 1), and another 50 in French (Figure 2). See Krotikov, V. A. "The Mendeleev Archives and Museum of the Leningrad University." Journal of Chemical Education 37, no. $12(1960): 627$.

${ }^{6}$ Examples of natural groups (i.e. elementary groups) are the alkaline metals and the halogens.
} 


\section{MeNDELEEV AND THE RARE-EARTH CRISIS}

When inspecting Mendeleev's Attempted System more closely, one cannot help it to be struck by the following intriguing fact: Normally, when reading from top to bottom, and from left to right, one should obtain an ever increasing atomic weight sequence. ${ }^{7}$ It appears however that this sequence gets interrupted twice. First, when passing from In (75.6, third column, bottom row) to Ti (50, fourth column, upper row), and a second time, when moving from Th (118, fourth column, bottom row) to $\mathrm{Zr}\left(90\right.$, fifth column, upper row). ${ }^{8}$ One possible way of restoring the sequence consists in eliminating a total of seven elements from the system - namely Er, Yt, In, Ce, La, Di, and Th. ${ }^{9}$ Indeed, if such is the case, the sequence passes from the unknown element with an atomic weight of 45 to $\mathrm{Ti}$ with an atomic weight of 50 , and from $\mathrm{Sr}$ with an atomic weight of 87.6 to $\mathrm{Zr}$ with an atomic weight of 90 - in accordance with the gradual increase in atomic weight.

\section{ESSAI D'UNE SYSTEHE DES ELEMENTS}

D APRES LEURS POIDS ATOMIQUES ETFONCTIONS CHIMIQUES,

par D. Mendeleeff,

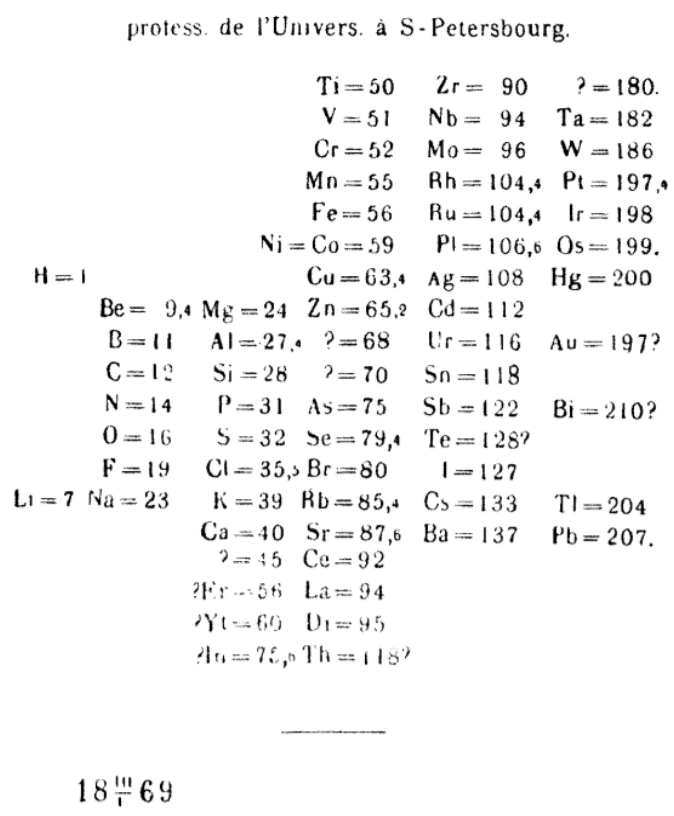

Figure 2. Essai d'une $[$ sic $]$ système des éléments d'après leurs poids atomiques et fonctions chimiques par D. Mendeleeff, professeur de l'Université à Saint-Pétersbourg. The French version of the Russian pamphlet, represented in Figure 1.

\footnotetext{
7 It would be scientifically more correct to use the term relative atomic mass. In this chapter however, the historical term atomic weight will be used throughout.

${ }^{8}$ Notice that the atomic weight sequence is violated two more times by the inversion of tellurium (Te) and iodine (I), and by the insertion of gold $(\mathrm{Au})$ and bismuth $(\mathrm{Bi})$.

${ }^{9} \mathrm{Yt}$ is an old symbol for yttrium $(\mathrm{Y})$. Di, on the other hand, was the symbol for the element didymium, which later turned out to be a mixture of praseodymium $(\mathrm{Pr})$ and neodymium $(\mathrm{Nd})$.
} 
It thus appears that "seven little studied elements remained outside of the table". ${ }^{10}$ This septuplet of homeless elements consisted of indium (In), thorium (Th) and the five rare earths - erbium $(\mathrm{Er})$, yttrium $(\mathrm{Yt})$, cerium $(\mathrm{Ce})$, lanthanum (La), and didymium (Di). ${ }^{11}$ Question marks and wrong atomic weights reigned in the last rows of Mendeleev's system, and a new place had to be found for the homeless septuplet. We will call this problematic accommodation issue the rare-earth crisis.

\section{I2 MENDELEEV's Experimental ResearCH IN 1869-1870}

Mendeleev published a trilogy of papers during the first period from 1869 till the first half of 1870. His first paper On the Correlation Between the Properties of the Elements and their Atomic Weights was drafted in the second half of February 1869 and put forth his Attempted System as a useful classification of the chemical elements (Figures 1, 2). ${ }^{12}$ During the month of August 1869, Mendeleev wrote a second paper summarising his experimental results Concerning the Atomic Volumes of Simple Bodies. ${ }^{13}$ He then turned to an investigation of the higher salt forming oxides and presented his results on October 2, 1869 during a meeting of the Russian Chemical Society in a paper

\footnotetext{
${ }^{10}$ Quoted from Brooks, N. M. "Developing the Periodic Law: Mendeleev's Work During 1869-1871.” Foundations of Chemistry $4(2002): 129$.

11 It must be remarked that terbium, another rare-earth element, was already known at the time when Mendeleev drew up his first periodic system, but Dmitrii Ivanovich decided to not include this element - following as a matter of fact Bunsen and Bahr's advice. Terbia had been discovered as early as 1843 by Mosander, but Mendeleev was not convinced that he was dealing with a genuine element. He therefore wrote the symbol of terbium (Ter.) in the marginalia of a piece of scrap paper when he was composing the Attempted System, but directly underneath this symbol Mendeleev scribbled that "it does not exist according to Bunsen" (не существует по бунзену). In writing this sentence, Mendeleev was in all probability referring to Bahr, J. F., and Bunsen, R. "Ueber Erbinerde Und Yttererde." Annalen der Chemie und Pharmacie 137 (1866a): 1-33. See also Bahr, J. F., and R. Bunsen. "Ueber Erbinerde Und Yttererde." Chemisches Central-Blatt 11, no. 8 (1866b): 118-125, and Bahr, J. F., and R. Bunsen. "Ueber Erbinerde Und Yttererde." Zeitschrift für Chemie 9 (1866c): 72-77.

12 Mendeleev, D. I. "On the Correlation between the Properties of the Elements and Their Atomic Weights." Zhurnal Russkogo Khimicheskogo Obshchestva 1, no. 2-3 (1869b): 35, 60-77. A reproduction of Mendeleev's table appeared in Mendeleev, D. I. "Versuch Eines Systems Der Elemente Nach Thren Atomgewichten Und Chemischen Funktionen.” Journal für praktische Chemie 106 (1869c): 251. A more complete abstract of Mendeleev's article can be found in Mendeleev, D. I. “Über Die Beziehungen Der Eigenschaften Zu Den Atomgewichten Der Elemente." Zeitschrift für Chemie 5 (1869d): 405406. See also Mendeleev's supplementary comments, made in autumn 1869, in Mendeleev, D. I. "On the Correlation between the Properties of the Elements and Their Atomic Weights." Zhurnal Russkogo Khimicheskogo Obshchestva 1 (1869f): 229-230, and an abstract in Mendeleev, D. I. "Die Beziehungen Zwischen Den Eigenschaften Der Elemente Und Ihrer Atomgewichten." Berichte der Deutschen chemischen Gesellschaft 2 (1869g): 553.

${ }^{13}$ Mendeleev, D. I. "Concerning the Atomic Volumes of Simple Bodies.” In Arb. II Kongr. Russ. Ärzt. Naturf., 1869e.
} 


\section{MendeleEv AND THE RaRE-EARTH CRISIS}

titled On the Quantity of Oxygen in Metal Oxides and on the Valency of the Elements. ${ }^{14}$ If his first paper had served to announce the discovery of the periodic law (and secure his priority), the remaining two offered an important illustration (and thus validation) of the concept of periodicity by his comprehensive study of both the physical and chemical properties of the elements.

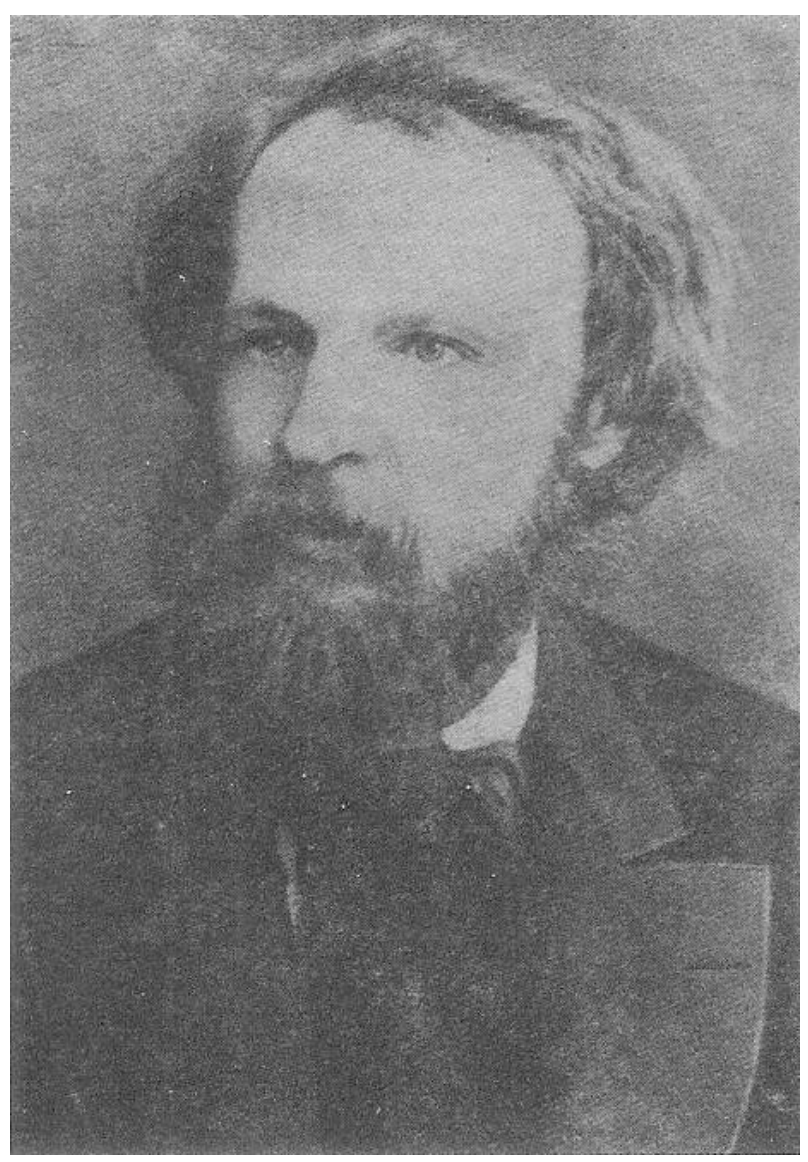

FIGURE 3. The 35 year old professor of general chemistry, Dmitrii Ivanovich Mendeleev in 1869.

Notwithstanding the importance of these experimental investigations, none of them was directly aimed at resolving the rare-earth crisis, and the septuplet of elements (Er, Yt, In, Ce, La, Di, and Th) remained outside the system. This does not imply however that Mendeleev wasn't pondering the issue. As will be argued in the following paragraphs, Mendeleev had been working ardently on the problem from a theoretical/philosophical line of approach, and there is much to be learned about the crux of the rare-earth crisis from a careful and meticulous examination of Mendeleev's trilogy of papers.

14 Mendeleev, D. I. "On the Quantity of Oxygen in Metal Oxides and on the Valency of the Elements." Zhurnal Russkogo Khimicheskogo Obshchestva 2 (1870a): 14-21. 


\section{Wrong Atomic Weights and Erroneous Valencies}

Due to the recent discoveries of the rare-earth elements, most of their chemical and physical properties were still shrouded in mist at the beginning of 1869, and Mendeleev had to manage with the limited information he had at his disposal. At the time, Mendeleev still adhered to the old Berzelian atomic weights for the rare-earth elements. Not one of these values corresponded to the real atomic weights however, as they were based on the erroneous assumption that most rare-earth elements were bivalent instead of trivalent. ${ }^{15}$ Their oxides were thus represented by the formula RO (with the higher oxide of cerium denoted as $\mathrm{R}_{2} \mathrm{O}_{3}$ ).

With the wrong atomic weights at hand, Mendeleev naturally failed to accommodate the rare earths, and he felt obliged to position them at the periphery of his Attempted System. If Mendeleev was to accommodate the rare earths properly, he would have to change their valency from 2 to 3. Even though Mendeleev would be the first in proposing this modification of valency number, he only did so at the end of the first half of 1870. Before that time that is, during the first period from 1869 till 1870), Mendeleev continued to look upon the rare-earth elements as being bivalent and he used the wrong atomic weights throughout.

This notwithstanding, Mendeleev certainly had doubts about the position of the rare-earth elements from the very outset. As he admitted in his 1869 article On the Correlation between the Properties of the Elements and Their Atomic Weights:

\footnotetext{
With respect to the position of some elements, there exists, quite understandably, complete uncertainty. In particular, this holds for those elements that are little studied and whose correct atomic weight has hardly been established with any certainty. Among these are, for example, yttrium, thorium, and indium. ${ }^{16}$
}

\footnotetext{
${ }^{15}$ The atomic weight $A W$ of an element $X$ is related to its valency $V$ via the general formula $A W(X)=E W(X) x V(X)$, with $E W$ the equivalent weight of $X$.

${ }^{16}$ Mendeleev, D. I. "On the Correlation between the Properties of the Elements and Their Atomic Weights." In Mendeleev on the Periodic Law, Selected Writings, 1869-1905, ed. William B. Jensen, 30. Mineola, New York: Dover Publications, Inc., 2002.
} 


\section{MENDELEEV AND THE RARE-EARTH CRISIS}

\section{The Companions of Cerium}

When LAVOISIER defined a chemical element in 1789, twenty six elements were actually known. Eighty years later, at the onset of 1869 , a total of thirty six elements had been added to the list. More and more chemists consequently felt the need for a systematic organisation. But instead of building a periodic table, as Mendeleev did in 1869, they felt inclined to group together elements with similar physical and chemical characteristics - ending up with a network of small, so-called natural groups. Well-known examples were the highly reactive halogens (F, Cl, Br, I) and the silver coloured and water-reactive alkali metals ( $\mathrm{Li}, \mathrm{Na}, \mathrm{K}, \mathrm{Rb}, \mathrm{Cs}$ ).

In the same way, Mendeleev recognised the similarity in chemical and physical properties of the rare-earth elements, and considered them to be members of a natural group as he proclaimed in his 1869 article. "Only with regard to some groups of elements are there no doubts that they form a whole and represent a natural order of similar manifestations of matter", Mendeleev explained. "Such groups are: the halogens, the alkaline earth metals, the nitrogen group, and also - in part the sulfur group, the companions of platinum, the companions of cerium, and a few others." 17

As a consequence, and in complete analogy with the alkali metals and the halogens, Mendeleev tried to accommodate the companions of cerium in the periodic table as a group. This fact is clearly exemplified in the Attempted System where the rare-earth elements (Er, Yt, Ce, La, and Di) are grouped together at the bottom of the system. Yet, Mendeleev promptly understood that the rare earths constituted a very special group of elements, and it seemed that the whole accommodation issue had its root in the puzzling nature of this elementary group. "A number of questions arise when all of the elements are arranged into one whole," Mendeleev said, "but the most interesting problem appears to me to be the arrangement of elements having such similarity as [...] cerium."18

\section{I5 Primary versus Secondary Classification}

In order to understand why Mendeleev discriminated this group from the other natural groups (such as the alkali metals and halogens), it will prove useful to explore the construction methodology of the periodic table. In short, a two-step process is needed in order to build a periodic table from scratch. First, all the elements have to be ordered according to increasing atomic weight. This primary classification results in a long horizontal sequence of elements, and has

\footnotetext{
17 Ibid., p 22. Emphasis added.

18 Ibid., p 31. Emphasis added.
} 
been called the Mendeleev Line by Henry Bent. ${ }^{19}$ It will be noted that certain chemical and physical properties of the elements recur periodically. Therefore, the second step, termed secondary classification, consists of partitioning this Mendeleev Line at certain well defined loci and placing the different sections (i.e. periods) underneath each other so that elements with similar properties will fall into the same vertical column, forming natural groups and representing the periodic law graphically.

It seems that Mendeleev exploited this construction methodology as well - more in particular when he created his first attempt. ${ }^{20}$ As Mendeleev explained:

My first attempt in this direction was as follows: I selected the substances with the smallest atomic weights and arranged them according to the magnitude of their atomic weights i.e. primary classification]. It became apparent that there existed, so to speak, a periodicity in the properties (even with regard to valency) of the simple substances [i.e.periodic law], when one element followed another according to a linear arithmetical arrangement of their atomic weights. [Secondary classification therefore led to]:

$\begin{array}{ccccccc}\mathrm{Li}=7 & \mathrm{Be}=9,4 & \mathrm{~B}=11 & \mathrm{C}=12 & \mathrm{~N}=14 & \mathrm{O}=16 & \mathrm{~F}=19 \\ \mathrm{Na}=23 & \mathrm{Mg}=24 & \mathrm{Al}=27,4 & \mathrm{Si}=28 & \mathrm{P}=31 & \mathrm{~S}=32 & \mathrm{Cl}=35,5 \\ \mathrm{~K}=39 & \mathrm{Ca}=40 & - & \mathrm{Ti}=50 & \mathrm{~V}=51 & - & -\end{array}$

In the division of elements with an atomic weight greater than 100 we encounter a completely analogous series:

$$
\mathrm{Ag}=108 \quad \mathrm{Cd}=112 \quad \mathrm{Ur}=116 \quad \mathrm{Sn}=118 \quad \mathrm{Sb}=122 \quad \mathrm{Te}=128 \quad \mathrm{~J}=127
$$

It is seen that $\mathrm{Li}, \mathrm{Na}, \mathrm{K}, \mathrm{Ag}$ show the same relationship to one another as do $\mathrm{N}, \mathrm{P}, \mathrm{V}$, Sb, etc [i.e. the formation of elementary groups as a result of secondary classification $]{ }^{21}$

\footnotetext{
${ }^{19}$ Bent, H. A. New Ideas in Chemistry from Fresh Energy for the Periodic Law. Bloomington, Indiana: AuthorHouse, 2006.

20 The first attempt is not to be confused with the Attempted System. Whereas the Attempted System (Figures 1, 2) represents the end-product of the process of discovery, Mendeleev most probably wrote down the first attempt at the very beginning of his quest for a classification of the elements.

${ }^{21}$ Mendeleev (1869b/t), op. cit., p 25. (see note 16
} 


\section{MendeleEv AND the RARE-EARTH CRISIS}

\section{I6 Primary versus Secondary Groups}

One can conclude at this point that natural, elementary groups (e.g. Li, Na, K, ..., Ag) are formed during the secondary classification. Within such a vertical group, the atomic weights of the congeners vary in a stepwise manner. ${ }^{22}$ In the case of the alkali metals $\{\mathrm{Li}, \mathrm{Na}, \mathrm{K}, \ldots, \mathrm{Ag}\}$, for example, one notices the following sequence of 'jumps' between the atomic weights: 723 ... 108. We will denominate such a natural group of elements by the term secondary group, the members of which will be called secondary elements. Hence, a secondary group is defined and recognised as follows:

1. Secondary groups are formed during the secondary classification of the elements;

2. There exists a stepwise relationship between the atomic weights of the congeners.

Some examples of secondary groups are the alkali metals, the alkaline earth metals, the halogens, and the noble gases.

In sharp contrast with this type of natural groups, some other groups, such as the cerium group $\{\mathrm{Ce}, \mathrm{La}, \mathrm{Di}\}$, are formed at an earlier stage of the construction methodology, namely during the primary classification. Worded somewhat differently, due to the fact that the elements constituting such groups succeed one another sequentially in the Mendeleev Line $($ e.g. Ce $=92, \mathrm{La}=94, \mathrm{Di}=$ 95), the formation of these groups will be noticed during the primary classification. Within such a horizontal group, the atomic weight of the congeners will remain almost constant. Thus in the case of the elementary group $\{\mathrm{Ce}, \mathrm{La}, \mathrm{Di}\}$, one observes the following sequence of atomic weights: 92 94 95. In what follows, such a natural group of elements will be denominated by the term primary group and their congeners by the name primary elements. Hence, primary groups are defined and recognised as follows:

1. Primary groups are formed during the primary classification of the elements;

2. There exists a steady, almost constant relationship between the atomic weights of the congeners.

\footnotetext{
22 Congeners are elements in the same group of the periodic system.
} 
Other examples of such primary groups are the iron group $\{\mathrm{Fe}=56, \mathrm{Ni}=59, \mathrm{Co}=59\}$, the platinum group $\{\mathrm{Pt}=197.1, \mathrm{Ir}=198, \mathrm{Os}=199\}$, the palladium group $\{\mathrm{Rh}=104.4, \mathrm{Rn}=104.4, \mathrm{Pl}=106.6\},{ }^{23}$ and the erbium group $\{\mathrm{Er}=56, \mathrm{Yt}=60\}$.

In conclusion, and keeping the above-stated crucial distinction between primary and secondary groups in mind, it should be relatively easy at this point to understand the 'special' character of the rare-earth groups. That is to say, since the rare-earth elements constituted two primary groups, $\{\mathrm{Ce}, \mathrm{La}, \mathrm{Di}\}$ and $\{\mathrm{Er}, \mathrm{Yt}\}$, Mendeleev considered these groups 'special' as their congeners exhibited atomic weight values which were very close to one another, a fact not to be observed in the 'normal' case of secondary groups where the congeners have radically different atomic weights. In his article On the Correlation between the Properties of the Elements and Their Atomic Weights, Mendeleev wrote:
A number of questions arise when all of the elements are arranged into one whole, but the most interesting problem appears to me to be the arrangement of elements having such similarity as iron, cerium, palladium, and platinum, since, in this case, elements close to each other in their nature also exhibit approximately the same atomic weights, a circumstance not to be observed in other rows, for in the latter similar elements possess different atomic weights. ${ }^{24}$

One can conclude that Mendeleev was blessed with a deep insight into the nature of and differences between elementary groups - a fundamental understanding, which in the eyes of the authors, is often lacking within the chemical community of the 21st century.

At least four important consequences can be drawn from the existence of primary groups: 1 . the problematic depiction of both primary and secondary groups in the periodic table, 2. the transitional function of primary groups, 3. the rare earth-transition metal analogy, and 4. the problematic nature of primary groups, undermining the periodic law and subverting the characterisation of the elements by their atomic weight.

\footnotetext{
${ }^{23}$ In Mendeleev's nomenclature, Rn represented ruthenium and Pl represented palladium.

${ }^{24}$ Mendeleev (1869b/t), op. cit., p 31. (see note 16) Emphasis added.
} 


\section{MENDELEEV AND THE RARE-EARTH CRISIS}

\section{TABLE LAYOUTS}

First of all, Mendeleev naturally wondered how one should depict both primary and secondary groups within his Attempted System. "Perhaps as a consequence of the closer study of these [primary] groups," said Mendeleev, "the system of elements arranged in [primary and secondary] groups will have to be changed such that in certain parts of the system the similarity between members of the horizontal rows will have to be considered [i.e. secondary group], but in other parts, the similarity between members of the vertical columns [i.e. primary group]." 25 Notice that, in comparison with Mendeleev's first attempt, all rows and columns have been interchanged in the Attempted System. Thus what used to be a vertical group of elements in the first attempt (e.g. Li, Na, $\mathrm{K}, . .$.$) has been transformed into a horizontal group in the Attempted System. As a result, all$ secondary groups are now lying horizontally. The primary groups, on the other hand, are laid out vertically in Mendeleev's Attempted System. Of course, whether a secondary group is lying horizontally (as in the Attempted System) or vertically (as in the first attempt) does not really matter. Of greater importance is the simultaneous existence of both primary and secondary groups in one classificatory system of the elements, and the way this is represented in the table layout.

\section{g8 Transitional Function of Primary Groups}

A more significant consequence of the existence of primary groups within the periodic system is their so-called transitional function. Mendeleev hit upon this substantial idea when he was examining the Attempted System. It appeared to him that the elements of the primary groups at the upper part of his system represented some sort of transition between two (sub)periods in the periodic table. "It must be remarked," he said, "that the upper members of the fourth column (Mn, $\mathrm{Fe}, \mathrm{Co}, \mathrm{Ni}, \mathrm{Zn}$ ) form a transition to the lower members of the (third) column in which $\mathrm{Ca}, \mathrm{K}, \mathrm{Cl}$ and similar elements are found. Thus the properties and atomic weights of cobalt and nickel, chromium, manganese, and iron represent a transition from copper and zinc to calcium and potassium." ${ }^{26}$ In all probability, this quotation lies at the origin of the term transition metals - a very powerful and important concept for the further development of the periodic table (see further). Nonetheless, at the beginning of 1869, Mendeleev's views on the matter were still rather intuitive

\footnotetext{
25 Loc. cit.

${ }^{26}$ Ibid., p 30. Emphasis added.
} 
and somewhat vague. Indeed, it was not easy to perceive the transitional function of the iron group, the palladium group, and the platinum group in the Attempted System. ${ }^{27}$

\section{The Rare Earth - Transition Metal Analogy}

As a consequence of fixing all his attention on the Attempted System, Mendeleev immediately recognised how the two primary groups, $\{\mathrm{Ce}, \mathrm{La}, \mathrm{Di}\}$ and $\{\mathrm{Er}, \mathrm{Yt}\}$, at the bottom part of his system helped in connecting the periods of the main core. It thus seemed that these primary groups were furnished with a transitional function as well. Due to the fact that both the transition metal groups (iron, palladium and platinum group) and the rare-earth groups (cerium and erbium group) exhibited a transitional function, Mendeleev quickly emphasised the similarity between these two sets of groups. Mendeleev first voiced these ideas in his 1869 article On the Correlation between the Properties of the Elements and Their Atomic Weights, where he wrote:

Perhaps for this reason [the] positions [of the iron group, the palladium group, and the platinum group] will have to be changed and, were they to be placed in the lower rows instead of the upper rows, then one would obtain three columns here which would, in many respects, exhibit similarities: one column containing cobalt, nickel, chromium, manganese, and iron [as well as Er, Yt, and In]; a second column containing cerium, lanthanum, and didymium, palladium, rhodium, ruthenium, and lastly, a third columns containing platinum, iridium, and osmium. ${ }^{28}$

The rare earth-transition metal analogy was further exemplified by Mendeleev in his article Concerning the Atomic Volumes of Simple Bodies (presented on 23 August 1869). Referring to the work of Wiedemann, Mendeleev emphasised the similarity in magnetic properties between the elements of the cerium group and of the iron group. Not only were all these elements "magnetic in their compounds", "their atomic magnetism [remained] similar when passing from one analogue to another." 29 Repeated references to the rare earth - transition metal analogy were also made in his

\footnotetext{
27 The transitional function of these primary groups must have manifested itself much more sharply during the construction process of the first attempt.

${ }^{28}$ Mendeleev (1869b/t), op. cit., p 30. (see note 16) Emphasis added.

29 Mendeleev, D. I. "Concerning the Atomic Volumes of Simple Bodies." In Arb. II Kongr. Russ. Ärzt. Naturf., 1869e. English translation by Trifonov, D. N. "Mendeleev and the Rare Earths." In Problems in the Study of Rare Earths, 28. Jerusalem: Israel Program for Scientific Translations, 1966.
} 


\section{MendeleEv AND THE RaRE-EARTH CRISIS}

article On the Quantity of Oxygen in Metal Oxides and on the Valency of the Elements (presented on 2 October 1869) and in the second volume of his Osnovy khimii, published in March 1870.

\section{Undermined Periodicity}

A fourth and last consequence of the existence of primary groups was their problematic nature undermining both the periodic law and the characterisation of elements as being defined by their atomic weight. Let us start with the subversion of periodicity. Mendeleev explained that "the arrangement of elements $[\ldots]$ according to the magnitude of their atomic weights corresponds to their so-called valencies and, to a certain degree, to the differences in their chemical characters". 30 According to Mendeleev, this "can be clearly seen in the row Li, Be, B, C, N, O, F": 31

$\begin{array}{cccccccc} & \mathrm{Li}=7 & \mathrm{Be}=9,4 & \mathrm{~B}=11 & \mathrm{C}=12 & \mathrm{~N}=14 & \mathrm{O}=16 & \mathrm{~F}=19 \\ \text { Valency } & 1 & 2 & 3 & 4 & 3 & 2 & 1\end{array}$

Thus, "Li and F are monovalent and are most widely separated with respect to electrochemical behaviour; $\mathrm{Be}$ and $\mathrm{O}$, which succeed them, are divalent; then come trivalent $\mathrm{B}$ and $\mathrm{N}$ and, in the centre, tetravalent carbon has its place." 32 This phenomenon appeared moreover to be "repeated in other rows". 33 "If we consider the distance between $\mathrm{Na}$ and $\mathrm{Cl}, \mathrm{Ag}$ and I, and others," Mendeleev remarked, "we also notice that the arrangement of elements according to the magnitude (of their atomic weights) corresponds in a certain degree to the valency and to the concept of affinity." 34 Due to the recurring nature of this phenomenon, Mendeleev concluded that, "when arranged according to their atomic weights, the elements display a distinct periodicity in their properties".35 Mendeleev's personal viewpoints on the periodic law were even more clearly stated in the first edition of his Osnovy khimii:

\footnotetext{
${ }^{30}$ Mendeleev $(1869 \mathrm{~b} / \mathrm{t})$, op. cit., p 33. (see note 16$)$

31 Loc. cit.

32 Ibid., p 27.

33 Ibid., p 33.

${ }^{34}$ Ibid., p 27.

35 Ibid., p 33.
} 
The regular and gradual changes in the size of atomic weights involves [...] the regular and gradual changes in the qualitative as well as in the quantitative capability of elements for compounds. In addition, there is a periodic repetition of both qualitative and quantitative characteristics, consonant with the gradual increase in atomic weight. This is the conclusion of all comparisons made in this regard and this opens, in my view, a new perspective on the elements. ${ }^{36}$

Mendeleev's insight in the subject matter, as well as the vital importance of the periodic law in classifying the chemical elements, cannot be overestimated. Nevertheless, and quite unfortunately, it could not be accredited a universal character, as it did not apply to the whole of chemical elements. After all, in the case of primary groups, there were of course "regular and gradual changes in the size of atomic weights", 37 but these were not accompanied by "the regular and gradual changes" 38 in the distinctive properties of the elements. In the case of the cerium group, for example:

$\begin{array}{cccc} & \mathrm{Ce}=92 & \mathrm{La}=94 & \mathrm{Di}=95 \\ \text { Valency } & 2 & 2 & 2\end{array}$

there appears to be a constancy in the valency number, although the atomic weights of the congeners are changing regularly and gradually. The same can be said for the iron group, the palladium group, the platinum group, and the erbium group. In conclusion, the generality of the periodic law got undermined due to the presence of primary groups in the periodic system. This was one of the core problems of the rare-earth elements, which lay at the basis of their problematic accommodation.

\footnotetext{
36 Mendeleev, D. I. Osnovy Khimii. 2 vols. 1st ed. St. Petersburg: Obshchestvennaia pol'za, 1868-1871. English translation by Trifonov, D. N. "Views of D. I. Mendeleev on Rare Earths." In Rare-Earth Elements and Their Position in the Periodic System. New Delhi: Indian National Scientific Documentation Centre, 1970. Emphasis in original.

37 Loc. cit.

38 Loc. cit.
} 


\section{MendeleEv AND the RaRE-Earth CRISIS}

\section{I11 Characterisation Issues: Primary versus Secondary Elements}

The dual sense of the epistemological concept of chemical elements has been the focus of much philosophical debate and research by contemporary philosophers of chemistry. Although this debate goes back to the 1931 paper by Paneth, ${ }^{39}$ the main idea was clearly already present in the Mendeleev corpus. ${ }^{40}$ It is therefore interesting to investigate to what extent the rare-earth crisis forced Mendeleev to change his points of view with regard to the nature and concept of elements.

Summarising Mendeleev's philosophical viewpoints, one could state that Mendeleev clearly recognised the dual sense of the nature of chemical elements. He thus clearly distinguished between the elements as simple substances and as basic substances. Simple substances could be characterised by the plethora of secondary properties (i.e. colour, taste, smell, etc.), and were therefore observable and isolable. Basic substances on the other hand were completely unobservable to our senses. This did not imply however that they were completely devoid of properties. Mendeleev was of the opinion that the more abstract, basic substances were characterised by the atomic weight, and he therefore used this property in accommodating all the chemical elements in his system. "In the proposed system the atomic weight of an element serves to determine its place" "41, Mendeleev explained. He concluded for that reason that "the magnitude of the atomic weight determines the character of an element to the same extent that the molecular weight determines the properties and many of the reactions of a compound substance." 42 An important consequence of taking the atomic weight as the characteristic property of basic substances was the

\footnotetext{
39 Paneth, F. A. "Über Die Erkenntnistheoretische Stellung Des Chemischen Elementbegriffs." Schriften der Königsberger Gelehrten Gesellschaft 8, no. 4 (1931): 101-125. An English translation can be found in Paneth, F. A. "The Epistemological Status of the Chemical Concept of Element (I)." The British Journal for the Philosophy of Science 13, no. 49 (1962a): 1-14 and Paneth, F. A. "The Epistemological Status of the Chemical Concept of Element (II)." The British Journal for the Philosophy of Science 13, no. 49 (1962b): 144-160. More recently, Paneth's paper has been republished in Paneth, F. A. "The Epistemological Status of the Chemical Concept of Element.” Foundations of Chemistry 5, no. 2 (2003): 113-145.

40 See Paneth, F. A. “Chemical Elements and Primordial Matter: Mendeleeff's View and the Present Position.” In Chemistry and Beyond: Selection from the Writings of the Late Professor F. A. Paneth, edited by Herbert Dingle and G. R. Martin, 53-72. New York: Wiley Interscience, 1965. See also Bensaude-Vincent, B. "Mendeleev's Periodic System of Chemical Elements." The British Journal for the History of Science 19, no. 1 (1986): 3-17, Scerri, E. R. "Realism, Reduction, and the "Intermediate Position"." In Of Minds and Molecules, New Philosophical Perspectives on Chemistry, edited by N. Bhushan and S. Rosenfeld, $51-$ 72. New York: Oxford University Press, 2000, Scerri, E. R. "Some Aspects of the Metaphysics of Chemistry and the Nature of the Elements." HYLE 11, no. 1-2 (2005): 127-145.

${ }^{41}$ Mendeleev $(1869 b / t)$, op. cit., p 26. Emphasis added. (see note 16)

${ }^{42}$ Ibid., p 27. Emphasis added.
} 
possibility of distinguishing between the (chemically and physically very similar) congeners of a certain elementary group in the periodic table. The natural group of alkali metals, for example:

$$
\mathrm{Li}=7 \quad \mathrm{Na}=23 \quad \mathrm{~K}=39 \quad \mathrm{Rb}=85.4 \quad \mathrm{Cs}=133
$$

consisted of five metals which shared a lot of similar properties - their metallic lustre, their low melting points and densities, their pronounced reactivity with respect to water, their rapidly oxidising character (tarnishing the metallic surface in a dull and lustreless grey colour), etc. It thus seemed that the differences in atomic weights were the only possible way to differentiate between these analogous elements. "Similar elements [in chemical and physical properties] possess different atomic weights", ${ }^{43}$ Mendeleev proclaimed.

But in the case of the cerium group $\{\mathrm{Ce}=92, \mathrm{La}=94, \mathrm{Di}=95\}$, the difference in atomic weights was scarcely noticeable. Indeed, one recalls that in sharp contrast with the secondary groups, which were characterised by a saltatory relationship between the atomic weights of the secondary elements, primary groups represented a steady and unchanging relationship between the atomic weights of the primary elements. As Mendeleev explicated in his Osnovy khimii: "In spite of the great similarity existing at present [between the chemical and physical properties of the congeners of the cerium group], there are no differences, or to speak precisely, there are no considerable differences in the salues of atomic weights of [these] similar elements." 44 "There are more examples of this kind", 45 wrote Mendeleev, who noticed that this observation was not limited to the members of the cerium group. It turned out that very similar apperceptions could be made with regard to the transition metal groups:

Such are nickel and cobalt, whose atomic weights are very close to each other; rhodium, ruthenium and palladium on the one hand, iridium, osmium and platinum on the other are also elements which closely resemble one another, and which have very similar atomic weights. Iron and manganese have similar properties and their atomic weights are also very similar. ${ }^{46}$

\footnotetext{
43 Ibid., p 31.

${ }^{44}$ Mendeleev (1868-1871), op. cit. (note 36) English translation by Trifonov (1970), op. cit., p 38. (note 36) Emphasis added.

${ }^{45}$ Loc. cit. English translation by Trifonov (1966), op. cit., p 27. (note 29)

${ }^{46}$ Loc. cit. Emphasis added.
} 


\section{MeNDELEEV AND THE RARE-EARTH CRISIS}

This implied that, in the case of primary groups, no differentiation between the congeners was possible anymore on the basis of their atomic weights. Otherwise stated, while secondary elements could still be characterised by their atomic weights, primary elements, on the other hand, could no longer be characterised by the atomic weight !

\section{I12 INTERNAL DiffERENCES OF MATTER}

The question naturally presented itself as to how one should differentiate between primary elements. According to Mendeleev, these elements were characterised by "internal differences of matter". ${ }^{47}$ The reason for the differences "is no longer the size and the weight of the atom," he said, "but obviously some other internal differences in the matter, constituting the atoms of these similar elements". ${ }^{48}$ This was comparable in some respects with isomeric substances, as well as with metameric compounds, which were defined by Mendeleev as having "the same weight of particle [i.e. molecular weight] but in which the distribution of parts or atoms inside the particle is undoubtedly not identical". ${ }^{49}$ While Mendeleev clearly stated that "elements of a similar nature, with similar atomic weights [i.e. primary elements], are somewhat similar to metameric compounds" $5^{0}$ it is not completely clear whether he actually believed in the complexity of atoms. After all, whereas Mendeleev referred to the "internal differences in the matter, constituting the atoms", Mendeleev also mentioned the "internal arrangement of atoms" at a certain point. Did he mean that the atoms were different due to an internal arrangement (thus believing in the complexity of atoms), or was he alluding to an internal difference in the arrangement of atoms inside a molecule? In any case, whether Mendeleev believed in the complexity of atoms or not, he definitely believed in the existence of atoms during the period 1869-1870. At that time, Mendeleev was giving his thoughts about the periodic system free rein. He was still prepared to accept the atomic hypothesis and he believed in both the chemical and physical atom.

In sharp contrast with the above-mentioned statement, the famous Mendeleev historian, Michael Gordin, claimed in his book on Dmitrii Mendelees and the Shadow of the Periodic Table that "it does not follow [...] that Mendeleev must have been thinking in terms of physical atomism when

\footnotetext{
47 Loc. cit. English translation by Trifonov (1970), op. cit., p 38. (note 36) Emphasis added.

${ }^{48}$ Loc. cit. English translation by Trifonov (1966), op. cit., p 28. (note 29)

${ }^{49}$ Loc. cit.

50 Loc. cit.
} 
he conceived his system. [...] Mendeleev's scepticism toward atomism sharply emphasises the difference between the present-day interpretation of the periodic system and Mendeleev's views of 1869. [...] For Mendeleev, any atoms that might exist had absolutely no substructure." 51 Bernadette Bensaude-Vincent as well, claimed that the elements "could never be divided" according to Mendeleev's opinion. ${ }^{52}$ Finally, the Japanese historian, Masanori Kaji asserted that "Mendeleev regarded atomic theory with caution" and Kaji therefore thought it reasonable "to suppose that [Mendeleev] refined the concept of the elements to bear an attribute of an individual chemical entity without employing the notion of atoms because of the supposed limitations of the atomic theory." 53

How to explain this difference in opinion? As we have argued elsewhere, ${ }^{54}$ Mendeleev did believe in atoms in 1869. But these viewpoints no longer surfaced in the papers which were written at a later stage of development of the periodic law (i.e. during the post-1869 period). At that time, Mendeleev had indeed radically changed his viewpoints concerning the existence of atoms. He thus emphasised in 1871 that "one cannot harmonise the periodic law and the atomic theory without upsetting the known facts." 55 Since the expression atomic weight implied "the hypothesis of the atomic structure of matter", Dmitrii Ivanovich proposed to replace this expression with "elementary weight" as it seemed to him that this would "avoid the concept of atoms when speaking of elements." 56 Such statements from the post-1869 period have led the majority of historians to the wrong conclusion that Mendeleev never believed in atoms. It appears that Nathan Brooks has been one of the few historians thus far in emphasising Mendeleev's speculations on the complexity of the elements in 1869. He thus clearly stated that "Mendeleev did not reject the complexity of elements in the first few years after his discovery of the periodic law." 57

\footnotetext{
51 Gordin, M. D. A Well-Ordered Thing: Dmitrii Mendeleev and the Shadow of the Periodic Table. New York: Basic Books, A Member of the Perseus Books Group, 2004. (pages 24-25) Emphasis in original.

52 Bensaude-Vincent, B., op. cit. p 7. (note 40)

53 Kaji, M. "D. I. Mendeleev's Concept of Chemical Elements and the Principles of Chemistry." Bulletin for the History of Chemistry 27, no. 1 (2002): 4-16. (page 6-7) Emphasis added.

54 Thyssen, P. “Mendeleev's Periodic Table and the 19th Century Debates on Atomism." In Wald, Positivism and Chemistry. Edited by M. Eisvogel and K. Ruthenberg. Würzburg: Königshausen and Neumann, 2014 (in press).

55 Mendeleev, D. I. "Die Periodischen Gesetzmässigkeit Der Chemischen Elemente." Annalen der Chemie und Pharmacie 8 (Suppl.) (1871c): 133-229. English translation in Mendeleev, D. I. "On the Periodic Regularity of the Chemical Elements." (1871c/t) In Mendeleev on the Periodic Law, Selected Writings, 1869-1905, ed. William B. Jensen, 38-109. Mineola, New York: Dover Publications, Inc., 2002. (page 58)

56 Ibid., p $40 \& 106$.

${ }^{57}$ Brooks (2002), op. cit., p 142. (note 10)
} 


\section{MendeleEv AND THE RaRE-EARTH CRISIS}

Thus ended the first period of Mendeleev's research which lasted from 1869 till the end of the first half of 1870. Mendeleev's viewpoints could be summarised as follows. According to his opinion, chemists had to draw a sharp distinction between primary (i.e. rare earths, transition metals) and secondary elements (i.e. alkali metals, halogens). Such a differentiation should also be made on the level of primary and secondary groups. Mendeleev thus concluded his paper of 1869 by noting that while all elementary groups were build from "elements exhibiting similarities in their chemical behaviour" differences in their nature would continue to exist, since the atomic weights of their congeners "are either approximately equal (as with Pt, Ir, Os) or [...] increase in a uniform manner (as with $\mathrm{K}, \mathrm{Rb}, \mathrm{Cs}) . " 58$

The essence of the rare-earth crisis rested on the fact that the septuplet of homeless elements constituted a primary group. Their problematic nature raised a number of serious problems. Both the principle of periodicity and the characterisation of primary elements on the basis of their atomic weights got undermined. Mendeleev was also tempted in drawing an analogy between the rare-earth elements and the transition metals on the basis of their transitional functions in the periodic system, and he started questioning the simplicity of these elements on a closer study of the primary groups. In conclusion, Mendeleev clearly grasped the causes of the problematic accommodation of the rare-earth elements in 1869. He nevertheless continued to use the old atomic weights and erroneous valencies for the rare-earth elements, and his unremitting adherence to the Attempted System moreover troubled his views with regard to the different relationships between the chemical and physical properties of the elements.

\section{$\S 2$ The PERIOD 1870-1871}

\section{I1 Natural System of the Elements}

Mendeleev had been working on the optimisation of the periodic law for quite some time now. He had always preferred the long form table (i.e. Attempted System, Figures 1, 2), but in November 1870, Mendeleev created a short form table - his Natural System of the Elements (Figure 4). This type of classification remained the standard format during the next one hundred years, and it succeeded in

\footnotetext{
58 Mendeleev $(1869 \mathrm{~b} / \mathrm{t})$, op. cit., p 33. (note 16
} 
exhibiting a number of new relationships between the chemical elements (as for example the close connection between the main-block elements on the one hand and the transition metals on the other).

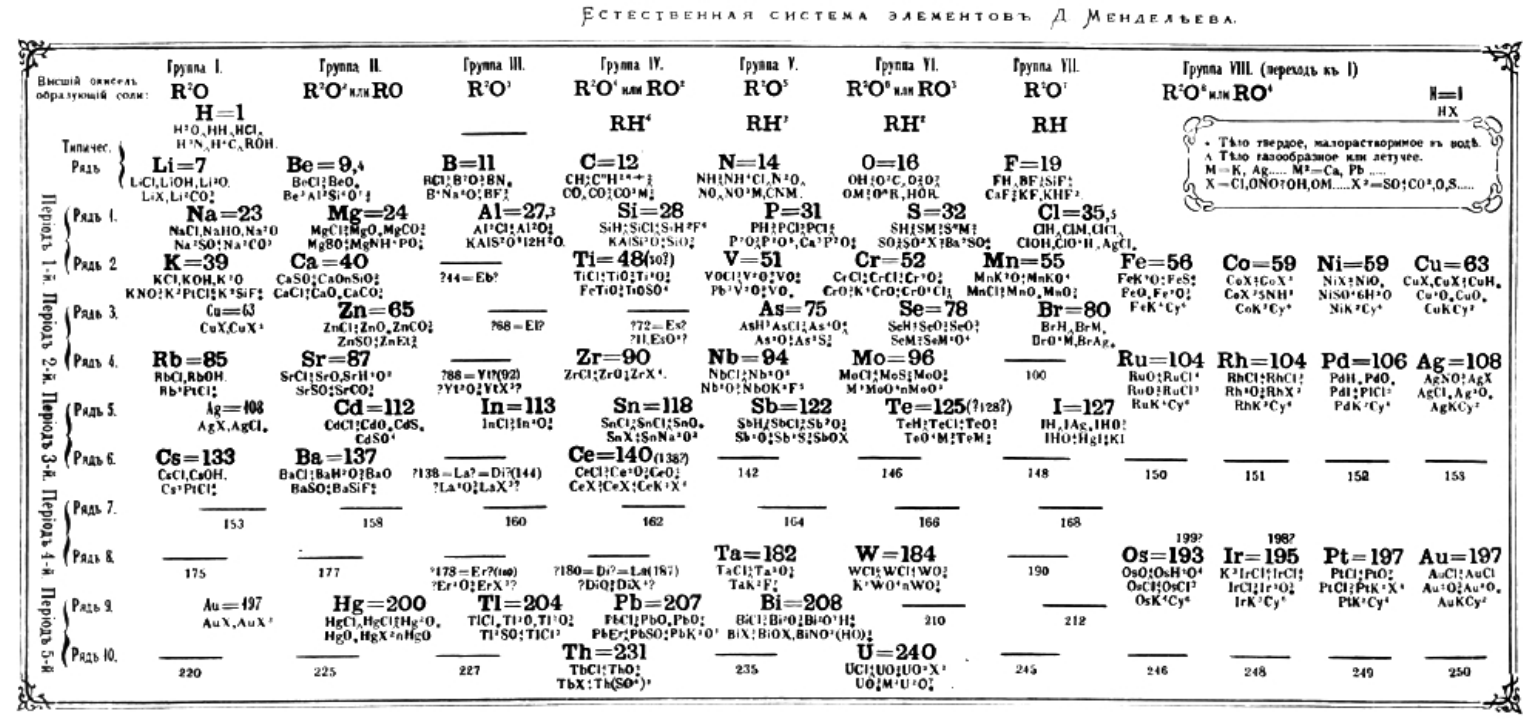

FiguRE 4. Mendeleev's Natural System of the Elements from 1870.

The Natural System consisted of two rows of typical elements $(\mathrm{H}$ till F) and 5 more periods which were further subdivided in an odd and even series of 7 elements each. Some elements could not be placed in any series and were therefore "arranged in order of their properties and atomic weights between the last member of the even series and the first member of the odd series" in an independent, eighth group. ${ }^{59}$ "In this manner", Mendeleev continued, "Fe, Co, and Ni are placed between $\mathrm{Cr}$ and Mn, on the one side, and $\mathrm{Cu}$ and $\mathrm{Zn}$, on the other, so as to form the following transition series:" 60

$$
\mathrm{Cr}=52 \quad \mathrm{Mn}=55 \quad \mathrm{Fe}=56 \quad \mathrm{Co}=59 \quad \mathrm{Ni}=59 \quad \mathrm{Cu}=63 \quad \mathrm{Zn}=65
$$

Two other triads of transition metals could be discerned in the Natural System: the elements Ru, Rh and $\mathrm{Pd}$, on the one hand, and $\mathrm{Os}$, Ir and Pt on the other (Figure 4).

\footnotetext{
59 Mendeleev (1871c/t), op. cit., p 48. (note 55). See also §1, 5 for an illustration of the construction methodology when building a short form table (i.e. first attempt).

${ }^{60}$ Loc. cit. Emphasis added.
} 


\section{MENDELEEV AND THE RARE-EARTH CRISIS}

Mendeleev emphasised that "the members of this group $[\ldots]$ resemble one another to the same extent as the corresponding members of the even series" ${ }^{61}$ with the only difference that they constituted three primary groups, instead of secondary groups as in the case of the elements from the groups I-VII. Notice also that these groups were horizontally orientated, just as Mendeleev had predicted back in 1869, when he said that perhaps the system of elements would have to be changed "such that in certain parts of the system the similarity between members of the horizontal rows [i.e. primary elements] will have to be considered, but in other parts, the similarity between members of the vertical columns [i.e. secondary elements]." ${ }^{2}$

One can conclude that Mendeleev was aided significantly by his construction of the short form table in defining the transition metals more clearly than before as those elements which connected the even and odd series.

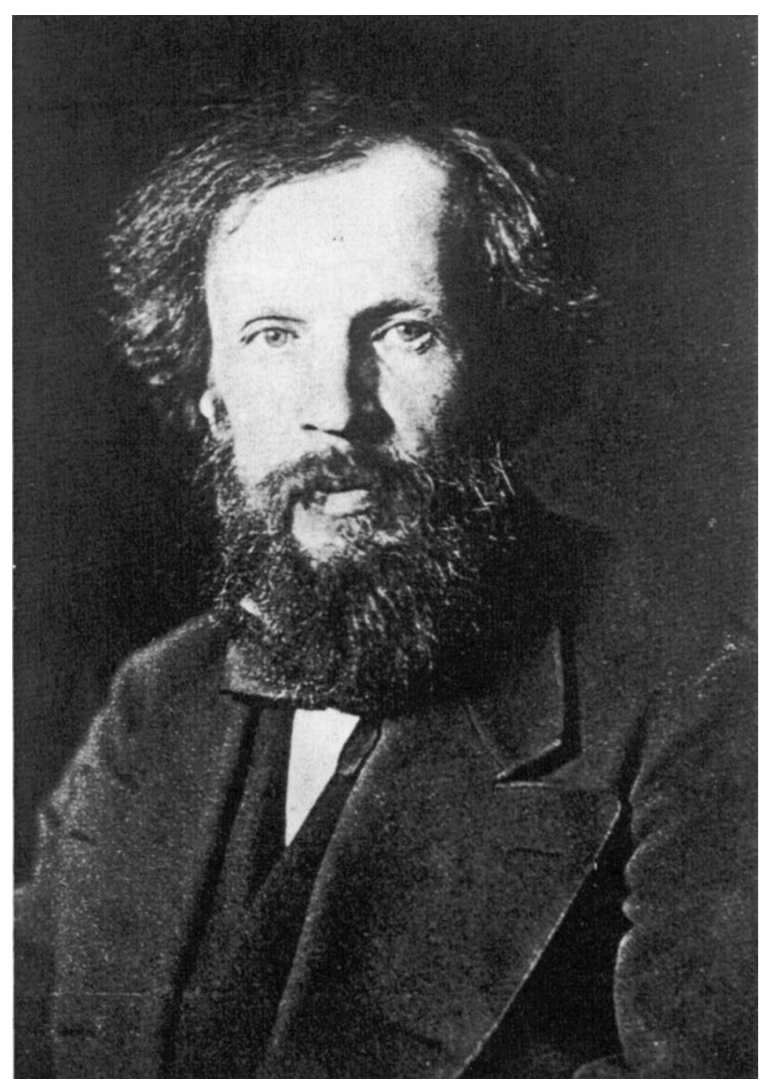

FIGURE 5. Dmitrii Ivanovich Mendeleev in the year 1870.

\footnotetext{
${ }^{61}$ Loc. cit.

${ }^{62}$ Mendeleev (1869b/t), op. cit., p 31. (note 16)
} 


\section{I2 Atomic Weight Corrections and VALEncy Shifts}

In that same year 1870, Mendeleev also wrote an article On the Placement of Cerium in the Periodic System of Elements, where he admitted that "the atomic weights of indium, uranium and cerium (and probably its associates) should be modified because these elements do not fit in on the basis of either the form of their oxides or their properties according to the periodicity indicated by me." 63 He realised that a change in valency would be necessary in order to correct the atomic weight values of the rare earths. The usual representation of their oxides by the formula RO had thus to be modified. Mendeleev was the first in assuming the rare earths to be trivalent, instead of bivalent, and he therefore proposed the general formula $\mathrm{R}_{2} \mathrm{O}_{3}$ for the rare-earth oxides. In the case of cerium, which represented two degrees of oxidation, Mendeleev proposed "that the ordinary degree of oxidation $[. .$.$] be allotted the formula \mathrm{Ce}_{2} \mathrm{O}_{3}$ ", while "the higher oxide will have the simple composition $\mathrm{CeO}_{2} .{ }^{\circ 64}$ Similar statements appeared in his article Concerning the Natural System of the Elements and Its Application in Determining the Properties of Undiscovered Elements. ${ }^{65}$ These valency shifts implied that the currently used atomic weights would have to be increased by a factor of 1.5 .

As Mendeleev wrote in his article On the Placement of Cerium in the Periodic System of Elements: "To confirm the above ideas, I undertook the problem of determining the heat capacity of the above-mentioned metals." 66 The experimental results, obtained in the fall of 1870 , were confirmed by the investigations of BUNSEN and spoke in the advantage of the corrected atomic weights.

\footnotetext{
63 Mendeleev, D. I. "On the Placement of Cerium in the Periodic System of Elements." Bulletin de l'Académie impériale des sciences de St.-Pétersbourg $16(1870 / 1871)$ : 45. English translation by Trifonov (1970), op. cit., p 40. (note 36) This paper was completed in November 24, 1870. Originally, Mendeleev had written one big article on "the system of the elements" but this was afterwards subdivided in Mendeleev (1870/1871) and Mendeleev (1871a). (note 65)

${ }^{64}$ Loc. cit. English translation by Trifonov (1966), op. cit., p 25. (note 29 )

65 Mendeleev, D. I. "Concerning the Natural System of the Elements and Its Application in Determining the Properties of Undiscovered Elements." Zhurnal Russkogo Khimicheskogo Obshchestva 3 (1871a): 7, 25-56. See also a German abstract in Mendeleev, D. I. "Über Das Natürliche System Der Elemente Und Seine Anwendung Zum Ermitteln Der Eigenschaften Unentdeckter Elemente." Berichte der Deutschen chemischen Gesellschaft 3 (1870b): 990-992.

${ }^{66}$ Mendeleev (1870/1871), op. cit. (note 61) English translation by Trifonov (1970), op. cit., p 40. (note 36)
} 


\section{MendeleEv AND THE RaRE-EARTH CRISIS}

\section{I3 Accommodating the Rare Earths Individualdy}

When the atomic weight of an element is changed, this logically implies a change in its position in the periodic table. Thus, due to the atomic weight corrections of indium, uranium, cerium, lanthanum, didymium, yttrium, erbium, and thorium, all eight elements had to be removed from their usual place, and they had to be accommodated differently. As can be seen from Figure 4, Mendeleev placed the rare-earth elements throughout the sixth, seventh, and eighth subperiods of his system in the groups I to VIII, as homologues of the other elements, according to a homologous accommodation methodology.

The accommodation of cerium went smoothly as Mendeleev had correctly determined its atomic weight and oxide formulae. According to the dualism of cerium, this rare-earth element exhibited two oxidation states $(+\mathrm{III}$ and $+\mathrm{IV})$, making its placement in the fourth group very natural. As Mendeleev reasoned in his article On the Placement of Cerium in the Periodic System of Elements:

Cerium will [have to] be located in accordance with the value of its atomic weight following caesium 133 and barium 137, and in accordance with the formula of its higher degree of oxidation it should be located in the titanium group, i.e., in the place IV-6. ${ }^{67}$

The placement of lanthanum, didymium and the other rare earths proved much more difficult. Mendeleev finally decided to locate yttrium in the place III-4. Lanthanum seemed to fit in the place III- 6 and didymium was finally given the element coordinates V-6, although Mendeleev was still playing with the idea of placing didymium in the same spot as lanthanum in III-6, as can be seen from Figure 4.

This homologous placement of the rare-earth elements shows to what extend Mendeleev's viewpoints had changed by the end of the first half of 1870 . What catches the eye is that Dmitrii Ivanovich had switched from placing the rare-earth elements as a group in the periodic system to an individual placement of each element separately. That is, by breaking up the natural group of

\footnotetext{
67 Loc. cit. English translation by Trifonov (1966), op. cit., p 25. (note 29) Due to the table layout - consisting of eighth groups (I-VIII) and ten series (1-10) - each element $(X)$ can be characterised by two coordinates, its group number $(G)$ and its series number $(S)$, as $G-S$. Sodium for example, is located in the first group and first series, and is therefore given the element coordinates I-1. Magnesium is located in the place II-1, and titanium is characterised by the element coordinates IV-2.
} 
rare earths, Mendeleev ended up with a set of distinct elements which he set out to accommodate on an individual basis in different groups of the system.

While this individual accommodation of the rare-earth elements represented an interesting step forward, it did not remove all problems. Mendeleev had always used "a web of analogies" in determining the positions of the chemical elements, but this methodology could no longer be applied in the case of the rare earths. As Nathan Brooks observed, "the rare-earth elements exposed a serious weakness in Mendeleev's approach to solving the placement of elements in his periodic system." 68 Not surprisingly, Mendeleev remained doubtful as to the new positions of the rare-earth elements.

Yet, the homologous placement offered a number of advantages as well. By emphasising the individuality of the rare earths, Mendeleev denied the existence of a primary group of rare-earth elements, which implied he could set aside all problems connected with the existence of such primary groups - in particular, the danger of undermined periodicity and the seeming impossibility of characterising the elements, as basic substances, by their atomic weights.

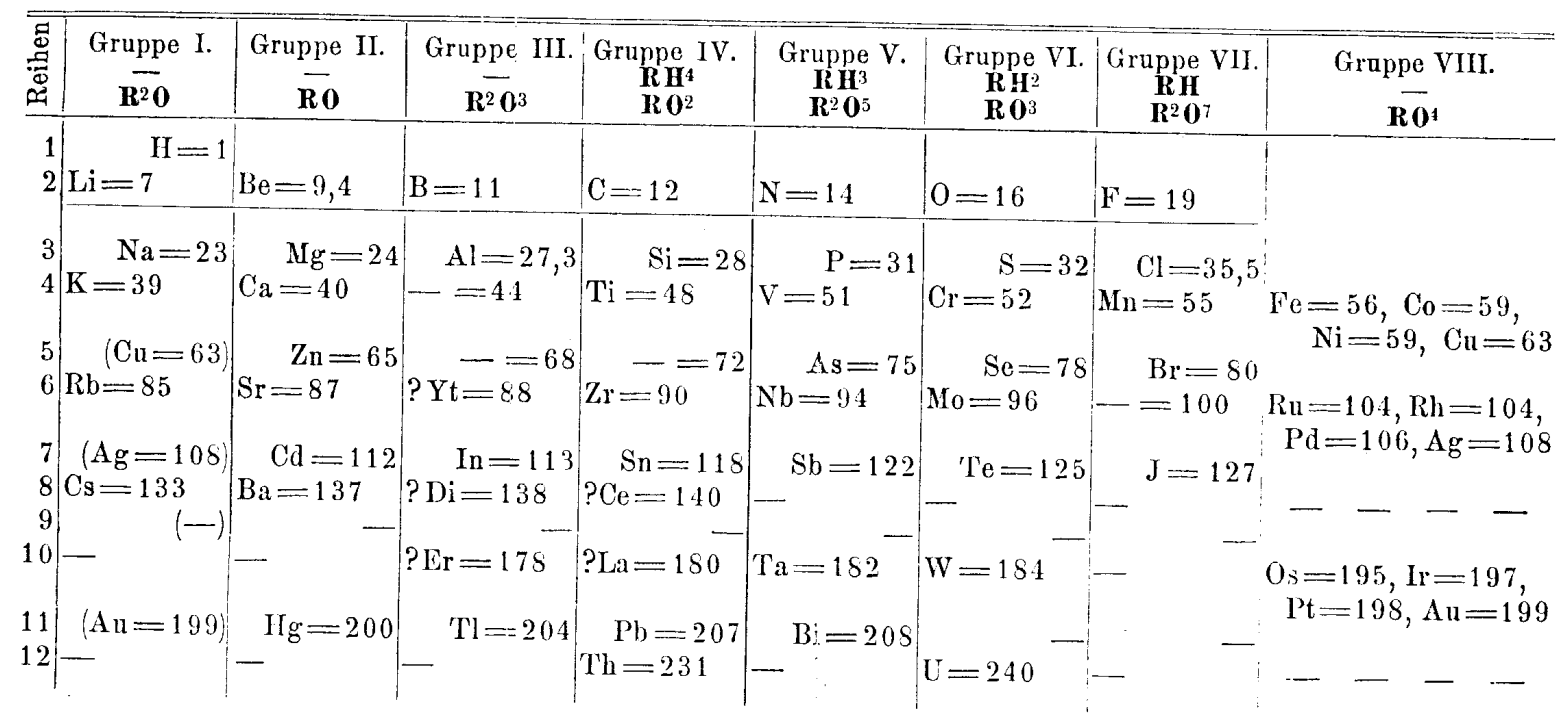

FiguRE 6. Mendeleev's Natural System of the Elements in 1871.

\footnotetext{
${ }^{68}$ Brooks (2002), op. cit., p 138-139. (note 10$)$
} 


\section{MendeleEv AND the RaRE-Earth CRISIS}

\section{I4 SAVING THE PERIODIC LAW}

Let us try to explain this last point somewhat better. One recalls that the periodic law got undermined by the existence of primary groups due to the fact that the "regular and gradual changes in the size of atomic weights" were not accompanied by "the regular and gradual changes" in the distinctive properties of the elements. ${ }^{69}$ Thus, in the case of the cerium group:

$\begin{array}{cccc} & \mathrm{Ce}=92 & \mathrm{La}=94 & \mathrm{Di}=95 \\ \text { Valency } & 2 & 2 & 2\end{array}$

the valency number (i.e. oxidation state) remained constant, instead of gradually increasing. If, however, these elements were accommodated as homologues of the 3rd, 4th and 5th group respectively, their valency also gradually increased from 3 to 4 and 5 , thus resolving the problem entirely:

$\begin{array}{cccc} & \mathrm{La}=138 & \mathrm{Ce}=140 & \mathrm{Di}=144 \\ \text { Valency } & 3 & 4 & 5\end{array}$

Mendeleev was swift at drawing an important conclusion from this: the typically trivalent rare-earth elements had to exhibit some higher oxidation states as well. Cerium, for example, was located in the fourth group with the tetrasalent transition metals titanium and zirconium, while didymium was taken to be a homologue of the pentavalent metals vanadium and niobium. Neither the tetravalency of cerium nor the pentavalency of didymium had as yet been established however, and Mendeleev therefore planned to start his own rare-earth research, in the hope of revealing these higher oxidation states. This would prove the validity of the homologous accommodation methodology and would rescue the periodic law from a painful exception.

\section{I5 Resolving the Characterisation Issues}

Previously, the differences in atomic weight values between lanthanum, cerium and didymium had been too small to differentiate between these three elements. This undermined Mendeleev's use of

\footnotetext{
${ }^{69}$ Mendeleev (1868-1871), op. cit. (note 36) English translation by Trifonov (1970), op. cit., p 38. (note 36$)$ Emphasis added.
} 
the atomic weight as the characteristic property of basis substances, and led Mendeleev to believing in physically real atoms and an internal matter constituting these atoms.

The individuation of the rare-earth elements in the second period turned these elements from primary into secondary elements. Since the transition metals continued to be primary elements, Mendeleev withdrew his claims about the rare earth - transition metal analogy. More importantly, by destroying the primary group of rare-earth elements, and accommodating them on an individual basis, Mendeleev created three new secondary groups, where the differences in atomic weight between lanthanum, boron and yttrium, for example, were big enough to use them as a characteristic, differentiating property. This removed the need to speculate about the existence of atoms, or the complexity of the elements.

\section{I6 MendeleEv's ACTIVE RarE-EARTH Research}

The improved format of Mendeleev's table had revealed a number of interesting relationships between the properties of the elements. Encouraged by this new information, Dmitrii Ivanovich began to focus all his attention on predicting the properties of the as yet undiscovered elements (i.e. eka-boron in III-2, eka-aluminium in III-3, and eka-silicon in IV-3, Figure 4). He finished writing his paper Concerning the Natural System of the Elements and Its Application in Determining the Properties of Undiscovered Elements on the $29^{\text {th }}$ of November 1870 and he presented his work during a meeting of the Russian Chemical Society in early December 1870.

With the predicted properties at hand, Mendeleev soon embarked upon his quest for the unknown elements. The position of eka-silicon (IV-3) implied that its properties would lie midway between those of titanium and zirconium, and Mendeleev therefore thought it best to initiate his hunt for this element in the minerals of titanium and zirconium. Two days after the meeting of the Russian Chemical Society, on the fifth of December 1870 to be exact, Mendeleev sent a petition to the rector of the University of St. Petersburg, K. F. KESSLER, requesting him a number of minerals for his future investigations. "My observation of the periodic dependence between the properties and the atomic weights of simple bodies gives the possibility to predict the existence and to guess the properties of some simple bodies that have not yet been discovered, about which I communicated at an extraordinary session of the Russian Chemical Society", said Mendeleev. ${ }^{70}$ "Desiring to verify at least part of the conclusions expressed [at this meeting], I need to undertake investigations of

\footnotetext{
${ }^{70}$ Brooks (2002), op. cit., p 138 . note 10
} 


\section{MeNDELEEV AND THE RARE-EARTH CRISIS}

several rare minerals, and therefore request that you contact the Mining Institute to ask them for some of these minerals needed for my scientific work which they have in stock."71

Mendeleev continued how especially important it was for him "to obtain as large an amount of titanium minerals as possible, together with their place of origin, if possible. Specifically: rutile $\left[\mathrm{TiO}_{2}\right]$, ilmenite $\left[\mathrm{FeTiO}_{3}\right]$, and also other minerals: zirconium $[\mathrm{Zr}]$, orthite, or cerite and eschynite." ${ }^{2}$ Dmitrii Ivanovich quickly obtained the requested minerals from P. A. KOCHUBEI and he read in the accompanying letter: "I am sending you according to your request the following minerals: 1) eschynite, 2) ilmenite, and 3) perovskite. The first and last minerals I have managed to obtain from stock with great difficulty - and this took place not without damage to the best specimens, but I will not complain if the results you will obtain justify your expectations." 73

The reason why Mendeleev asked for some specimens of rutile, ilmenite and zirconium should be clear by now. But why was he in need of orthite, cerite, and eschynite? Both cerite and eschynite are rich in cerium (and to a lesser degree also in lanthanum and yttrium). The mineral orthite, on the other hand, is not only abundant in cerium, it also contains substantial amounts of the other rare-earth elements. Obviously, Mendeleev was not only planning to discover the unknown ekasilicon, he also hoped to perform some experimental research on the rare earths in order to resolve their problematic accommodation.

As soon as he had received his mineral supplies from the Mining Institute and the Russian Technical Society, Dmitrii Ivanovich enthusiastically embarked upon his quest for eka-silicon and he also initiated his investigations of the rare-earth elements - trying to prove the validity of his homologous accommodation methodology. As Gordin stated, "he even refused a post at Moscow University on the grounds that he did not want to give up his current research on the rare earths." ${ }^{24}$ Mendeleev pasted two periodic tables in his laboratory notebooks and he used them as a newfangled and powerful paper tool to guide his modern chemical research (Figure 7 ). ${ }^{75}$ As can be seen from the figure, Mendeleev had scribbled some of the rare-earth elements in thick red characters in the third group of his natural system.

According to Nathan Brooks, "Mendeleev spent considerable time trying to separate the four known rare-earth elements over the course of about one year, but he only met with failure. The difficulty was compounded because two of these rare earths (didym and erbium) later turned out to

\footnotetext{
${ }^{71}$ Loc. cit.

72 Loc. cit.

${ }^{73}$ Loc. cit.

${ }^{74}$ Gordin (2004), op. cit., p 43. (note 51)

${ }^{55}$ Loc. cit.
} 
be mixtures of several elements and not pure elements." 76 As a consequence "Mendeleev's patience with this research agenda ran out quickly" ${ }^{77}$ On the twentieth of December 1871, after scribbling no more than 67 pages in his lab book, Mendeleev decided to abandon all research on the rareearth metals, and he set off on a gas project in search of the luminiferous ether. "On this date, on this page," said Gordin, "we can pinpoint the death of all research by Mendeleev on the periodic system. Gas expansion, not elemental discovery, became his goal."78 At the upper left hand corner of his short form system, above hydrogen, Dmitrii Ivanovich had scrawled: "The ether is lighter than all of them by a million times" (Figure 7). ${ }^{79}$

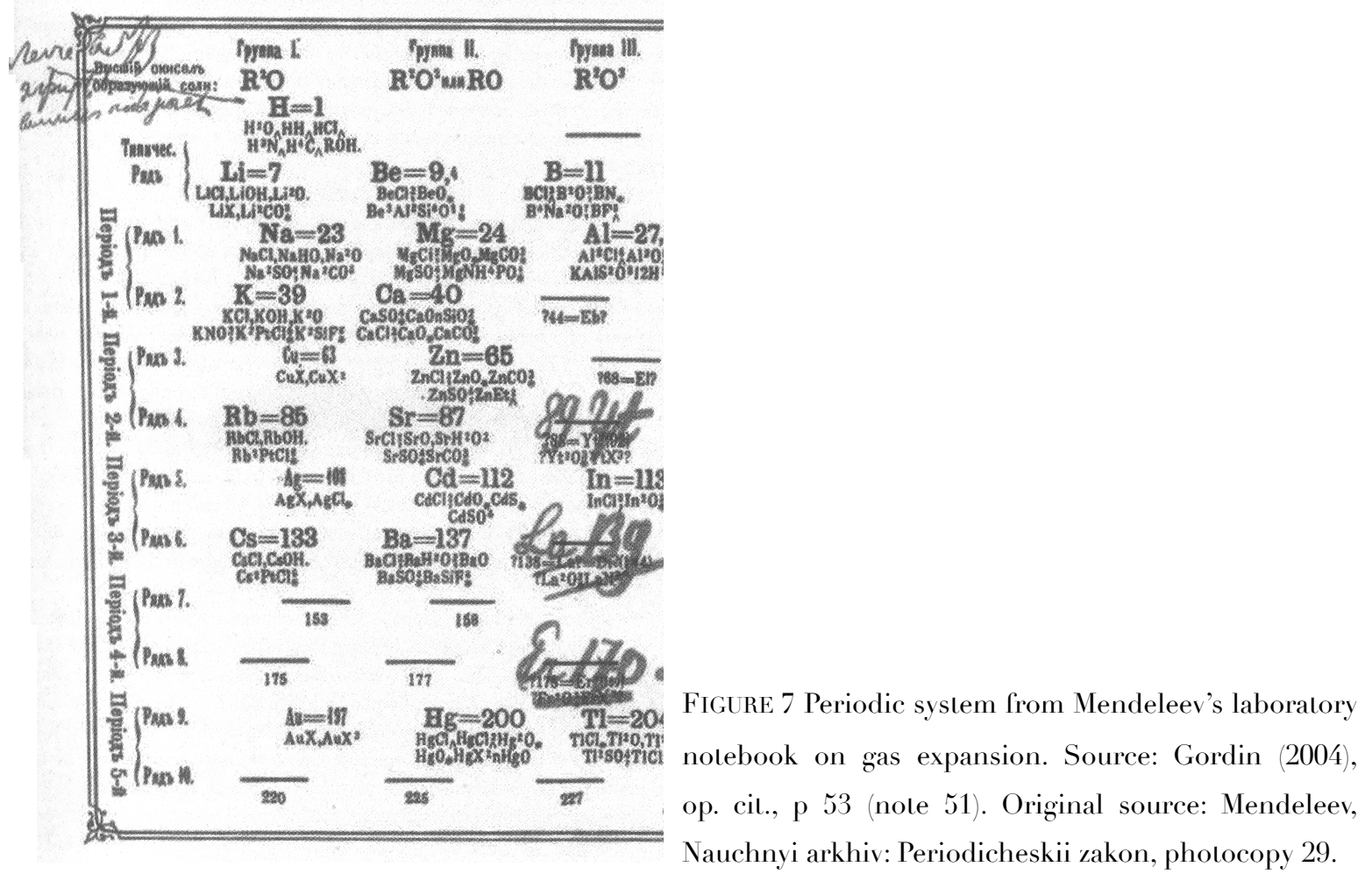

Thus ended Mendeleev's experimental research on the periodic law as well as his rare-earth investigations. In July 1871, Mendeleev composed his German landmark article on the periodic

\footnotetext{
${ }^{76}$ Brooks (2002), op. cit., p 138. (note 10

77 Gordin (2004), op. cit, p 50. (note 51)

${ }^{78}$ Loc. cit.

${ }^{79}$ Ibid., p 52.
} 


\section{MendeleEv AND the RaRE-Earth CRISIS}

law, which was translated into German by FELIX WREDEN and which appeared in Liebig's Annalen in November 1871 - symbolising Mendeleev's last research paper on the periodic law. ${ }^{80}$

From all the papers Mendeleev had written in the period 1869-1871, this paper proved most valuable for the next generation of chemists who were on the verge of embarking on their own rare-earth studies. A definite proof as to the validity of the homologous accommodation methodology was still lacking. "It is here", Mendeleev said, "more than elsewhere in the system of elements, that new investigations are to be desired and for which the periodic law provides guidance." 81

About six years later, the young Czechoslovakian chemist, BOHUSLAV BraunER, discovered Mendeleev's “wonderful communication”. It made such a profound impression on him that he fixed his life's aim at that very moment: "it was the experimental research of the solution of the following problems: What is the position of the so called rare elements and especially those of the rare earths in Mendeleev's system?" 82 Brauner would become the main defender of the periodic system in the late nineteenth century, and his rare-earth research became of the utmost importance for the further resolution of the rare-earth crisis. But that is another story. ${ }^{83}$

\section{$\S 3$ COnCLusions}

Dmitrii Ivanovich Mendeleev definitely grasped the essence of the rare-earth crisis better than anyone else. His train of thought had been meticulously written down in a number of papers on the periodic law during the period 1869-1871. But Mendeleev not only circumscribed the rareearth problem, he also significantly aided in partly resolving the crisis. Thus Mendeleev corrected the atomic weight values of the rare-earth elements by increasing their valency from 2 to 3 , and he attempted to accommodate these metals on an individual basis according to a homologous placement. From the very beginning in 1869, Mendeleev had a sound conception of the difference

\footnotetext{
${ }^{80}$ Mendeleev (1871c/t), op. cit. (note 55)

${ }^{81}$ Mendeleev (1871c/t), op. cit., p 81. (note 55)

${ }^{82}$ Brauner, B. "D. I. Mendeleev as Reflected in His Friendship to Professor Bohuslav Brauner." Collection of Czechoslovak Chemical Communications 2 (1930): 219-243 (page 231).

83 Thyssen, P., and K. Binnemans. "Accommodation of the Rare Earths in the Periodic Table: A Historical Analysis." In Handbook on the Physics and Chemistry of Rare Earths, edited by K. A. Gschneidner, 41, 1-94. Burlington: Academic Press, 2010 .
} 
between primary and secondary groups of elements. He discerned basic substances from simple substances, and he knew the advantages and disadvantages of both the short and long form tables.

Since Mendeleev's viewpoints underwent some crucial changes around the second half of 1870 , this paper was divided in two main parts. The first period was characterised by Mendeleev's use of a long form periodic table (the Attempted System, Figures 1,2) and his attempt to accommodate the rare-earth elements as a group. The rare earths thus constituted a primary group of primary elements, undermining both the periodic law and the characterisation of basic substances by their atomic weights. The old, Berzelian atomic weights were used throughout and Dmitrii Ivanovich endeavoured to grasp the rare-earth crisis by drawing an analogy between these elements and the so-called transition metals.

In sharp contrast with the first period, the second period was characterised by Mendeleev's use of a short form periodic table the Natural System, Figures 4, 6). He aimed at an individual accommodation of the rare-earth elements, by converting the rare-earth elements from primary to secondary elements and thus resolving the undermined periodicity and characterisation issues. He modified the atomic weights by a valency shift, and withdrew his claims about the rare earthtransition metal analogy.

To a large extent, the aim of this paper has been to demonstrate how bold and daring Mendeleev's statements were in 1869. At that time, Mendeleev loved to give his thoughts free rein and he had all faith in the successful future development of his system. He clearly believed in atoms and even played with the idea of an internal matter constituting these atoms thus pointing to the complexity of atoms). In sharp contrast with Mendeleev's character in 1869, the more familiar and conservative Mendeleev of the post-1869 period was very sceptic about the possible existence of physical atoms (not to mention his disbelief in Prout's hypothesis and the complexity of atoms $).{ }^{84}$

\section{ACKNOWLEDGMENTS}

The authors would like to extend a very special thanks to the Mendeleev historian, Michael Gordin, for his invaluable input, detailed comments, feedback and encouraging suggestions on a previous version of this paper. This paper was first presented by Pieter Thyssen at the 13th ISPC

\footnotetext{
84 Thyssen, P. “Mendeleev's Periodic Table and the 19th Century Debates on Atomism." In Wald, Positivism and Chemistry. Edited by M. Eisvogel and K. Ruthenberg. Würzburg: Königshausen and Neumann, 2014 (in press).
} 


\section{MeNDELEEV AND THE RARE-EARTH CRISIS}

Summer Symposium of the International Society for the Philosophy of Chemistry in Philadelphia, in August 2009. Pieter warmly thanks the participants of this conference for the many insightful discussions. Eric Scerri, Eugen Schwarz and Robin F. Hendry, in particular, are acknowledged for their help. Thanks are also due to the late Johannes W. Van Spronsen and Masanori Kaji who kindly provided some of the primary source material. Part of this work was done while Pieter Thyssen was working as a fellow in the Othmer Library of the Chemical Heritage Foundation (CHF) in Philadelphia, thanks to the generous financial support, provided by the Chemical Heritage Foundation and the Research Foundation Flanders (FWO). 